\title{
Effects of acute stress on social behavior in women
}

\author{
Bernadette von Dawans ${ }^{\mathrm{a}, \mathrm{b}, *}$, Beate Ditzen ${ }^{\mathrm{c}}$, Amalie Trueg ${ }^{\mathrm{a}}$, Urs Fischbacher ${ }^{\mathrm{d}, \mathrm{e}}$, Markus \\ Heinrichs $s^{a}$ \\ a Department of Psychology, Laboratory for Biological and Personality Psychology, University of Freiburg, D-79104 Freiburg, Germany \\ ${ }^{\circ}$ Department of Psychology, Biological and Clinical Psychology, University of Trier, D-54290 Trier, Germany \\ ${ }^{\mathrm{c}}$ Institute of Medical Psychology, Heidelberg University, D-69115 Heidelberg, Germany \\ d Department of Economics, University of Konstanz, D-78457 Konstanz, Germany \\ e Thurgau Institute of Economics, CH-8280 Kreuzlingen, Switzerland
}

\begin{abstract}
A B S T R A C T
Acute stress is known to increase prosocial behavior in men via a "tend-and-befriend" pattern originally proposed as a specifically female stress response alongside the fight-or-flight response. However, the direct effects of acute stress on women's social behavior have not been investigated. Applying the Trier Social Stress Test for groups (TSST-G), 94 women were confronted with either a stress or control condition. We repeatedly measured their subjective stress responses, salivary cortisol, and heart rate, and investigated their level of trust, trustworthiness, sharing, punishment and non-social risk using social decision paradigms. We detected significant increases in all stress parameters, as well as the wish for closeness during the stress condition. Acute stress exposure elevated prosocial trustworthiness and sharing without affecting non-social risk behavior. These results are in line with findings on the effects of stress in men, and further validate the tend-and-befriend pattern as one possible behavioral response during stress in humans.
\end{abstract}

\section{Introduction}

Stress is an omnipresent phenomenon in our lives. With its consequences on a subjective level and various physiological adaptations (eg, increases in cardiovascular activity, cortisol secretion or immune system changes), it reveals a strong impact on wellbeing and health (Chrousos, 2009; Foley and Kirschbaum, 2010; Kemeny and Schedlowski, 2007; Ménard et al., 2017), especially when it concerns chronic states of stress or repeated, intense stressful situations entailing few options to recover (Karatsoreos and McEwen, 2011; McEwen et al., 2015). However, acute stress also influences cognition and behavior (Schwabe and Wolf, 2010, 2009). Sincethe stress response shifts the physiological system to a state of higher vigilance and physical capacity, this state and possible behavioral consequences were interpreted from an evolutionary perspective: the term 'fight-or-flight response' circumscribes the two behavioral routes a stressed person (facing a threat) can take (Cannon, 1939). In addition a freeze modus is often added to the model in terms of "freeze-fight-or-flight" (Roelofs, 2017). But modern western society humans rarely face wild dangerous animals, and the dilemma to choose fight or flight as consequences of acute stress appears to offer neither always appropriate nor effective behavioral patterns for all stressful situations. By introducing the tend-and-befriend pattern (Taylor et al,, 2000) Shelley Taylor offers an alternative response pattern initially delineated for women but later expanded to men, too (Taylor, 2006). She describes the pattern as an additive to the fight-or-flight response with underlying mechanisms involving oxytocinergic, opioid or dopaminergic actions. Evidence for tend-and-befriend reactions to stress have recently been documented. We identified higher levels of trust, trustworthiness, and sharing during acute stress in men (von Dawans et al., 2012). In addition, Berger and colleagues (Berger et al., 2016) demonstrated that the cortisol response level in the stress condition correlated positively with the psychological closeness to the interaction partner in the fast-friends-procedure, an interaction paradigm to investigate social interaction in the lab (Aron et al., 1997). In a recent study in women, Ditzen and coworkers found greater preferences towards feminized male faces after stress, suggesting that stress accelerates the focus on female (eg, affiliative) attributes (Ditzen et al., 2017). Moreover, acute stress even increases empathy (Wolf et al., 2015). Although the concept "tend-andbefriend" was originally introduced to describe female behavior, and studies already validated the tend-and-befriend pattern in women especially in the domain of social cognition (Smeets et al., 2009; Tomova et al., 2017, 2014), there is to the best of our knowledge no validation regarding the social behavioral domain. We therefore wanted to specifically test the influence of acute stress on social behavior in women using an experimental social interaction paradigm from behavioral economics including trust, trustworthiness, sharing, punishment, and non-social risk that we already applied to men

\footnotetext{
* Corresponding author at: Department of Biological and Clinical Psychology, University of Trier, D-54290 Trier, Germany.

E-mail address: vondawans@uni-trier.de (B. von Dawans).
} 
(von Dawans et al., 2012). We specifically focused on sex hormones that might mediate potential effects on social behavior. For this we included and systematically compared one group of women voluntarily taking hormonal contraceptives to one group of naturally cycling women who were voluntarily not taking hormonal contraceptives.

\section{Materials and methods}

\subsection{Participants}

We tested 120 healthy, heterosexual women without mental or physical illness, not taking any medication (besides the contraceptive in the contraception group) and all with a BMI $>18$ and $<30$. Other exclusion criteria were pregnancy, shift work, or smoking more than four cigarettes per day, or prior participation in either the Trier Social Stress Test (TSST) (Kirschbaum et al., 1993) or the Trier Social Stress Test for Groups (TSST-G) (von Dawans et al., 2011). Participants either were not using hormonal contraceptives and had a regular cycle, or were on oral contraception (OC) for a minimum of six months. With OCs, we only included monophasic formulas involving under $50 \mu \mathrm{g}$ ethinylestradiol (Kirschbaum et al., 1999). We tested women without contraception in the luteal phase of their menstrual cycle. Women taking OC were tested in week two or three of their pill intake phase. Participants had to provide us with all the details about their cycle or pill usage, and were invited to the lab accordingly. In addition, we assessed their level of premenstrual symptoms and asked whether their menses has already started on the day of the experiment. We had to exclude 15 participants from the analyses because they claimed to be having their period on the day of the experiment. One participant was invited at the wrong time window and one participant withdrew her participation during the stress procedure. Another seven participants were excluded because they showed a level of psychiatric symptoms more than two standard deviations above the mean, and two failed to understand the experimental procedure well enough. That left us with a total of 94 women aged a mean 23 years $(S D=2.794)$ as target participants. Target participants received a flat fee of $25 €$ and could earn additional money in the social-interaction paradigms. On the mean level, target participants were reimbursed with $30.75 €(S D=0.74 €)$. The group sizes and characteristics are in Table 1. A second group of female participants was recruited as interaction partners for the target participants. This second group did not complete the stress or control condition of the TSST-G or other measures, and was involved only in the interaction games. Members of this second group received a flat fee of $2 €$ and could earn additional money in the social-interaction paradigms. The second group earned $7.93 €(S D=0.92)$ on the mean level.

\subsection{Social and non-social decision paradigms}

To investigate the effects of acute stress on social behavior in women, we used a design from behavioral economics already tested in men (von Dawans et al., 2012). It includes a range of decisions to study prosocial behavior: trust, trustworthiness, and sharing (with four decisions each), aggressive behavior: punishment (four decisions), and non-social risk behavior (eight decisions). Fig. S1 illustrates one example for each paradigm (all parameters are stated in the supplementary materials). Women always interacted anonymously with real female interaction partners who were not part of the stress (or control) condition. Each decision reflected a binary choice (eg, trust vs. no trust, trustworthiness or no trustworthiness). Both the trust game and trustworthiness game were sequential two-player games. The player with the first move had to choose between trust or no trust. If the first player chose trust, more points could be scored if the second player was trustworthy. Participants played four variants of the game as player with the first move (trust) and four variants of this game as player with the second move (trustworthiness). The second player had to decide whether to be trustworthy or not before being informed about the firstmover choice. This is called the strategy method.

The punishment game was again a sequential two-player game. The interaction partner always had the first move, and she could decide how to distribute 50 monetary units (MU). She could either choose a fair or a given unfair distribution. If she chose the fair offer, there was no further choice. But if she chose the unfair offer, the target participant could either accept the offer or punish the interaction partner by refusing the offer. In this latter case, both players received 0 MU. Again we applied the strategy method: the target participants decided whether to reject the unfair offer before knowing what the first player had chosen.

In the sharing game, the target participant could choose between two options: a) keeping all MUs for herself or b) choose a given share. There was no opportunity for the interaction partner to influence the outcome.

In the nonsocial risk game, the target participant played on her own. In each of the eight rounds, she could choose between a low risk gamble or a highly risky one. Next, the participant rolled a die to determine the outcome of the chosen gamble: Rolling a 1, 2, or 3 resulted in the higher outcome, whereas rolling a 4,5 , or 6 resulted in the lower outcome.

The games were played in two sets. Each set involved a total of 12 decision rounds -6 were prosocial ( 2 rounds of the trust game, 2 of the trustworthiness game, and 2 of the sharing game), 2 were antisocial (punishment game), and 4 were nonsocial (nonsocial risk game)-and each round had a different payoff. To ensure all decisions were made under acute psychosocial stress or under the effects of a control condition, we instructed the target participants to complete the first set of decisions immediately after the first stressor (or control condition) and the second set of decisions immediately after the second stressor (or control condition) (see Procedure). The set order was randomized.

For the analyses, the number of decisions reflecting trust, trustworthiness, sharing, or punishment was counted. Thus, for these measures, the maximum score was 4 , and the minimum score was 0 . For the nonsocial risk game, 1 point was given for each decision in favor of the risky gamble, which resulted in a minimum of 0 and a maximum of 8 .

Table 1

Group characteristics with mean values \pm SD in each group.

\begin{tabular}{|c|c|c|c|c|c|}
\hline & $\begin{array}{l}\text { Control_NoOC } \\
(n=26)\end{array}$ & $\begin{array}{l}\text { Control_OC } \\
(\mathrm{n}=24)\end{array}$ & $\begin{array}{l}\text { Stress_NoOC } \\
(n=19)\end{array}$ & $\begin{array}{l}\text { Stress_OC } \\
(\mathrm{n}=25)\end{array}$ & $\mathrm{p}$ - value \\
\hline $\begin{array}{l}\text { Age } \\
\quad \text { (years) }\end{array}$ & $23.08 \pm 2.95$ & $23.08 \pm 2.59$ & $23.68 \pm 3.15$ & $22.32 \pm 2.54$ & all $\mathrm{p} n \mathrm{~ns}$ \\
\hline BMI & $21.15 \pm 2.34$ & $21.36 \pm 1.79$ & $21.71 \pm 2.11$ & $21.30 \pm 2.21$ & all p ns \\
\hline PMS & $22.31 \pm 14.35$ & $21.75 \pm 17.91$ & $23.79 \pm 18.75$ & $16.88 \pm 11.67$ & all p ns \\
\hline BSI & $0.47 \pm 0.31$ & $0.53 \pm 0.34$ & $0.49 \pm 0.35$ & $0.38 \pm 0.25$ & all $\mathrm{p}$ ns \\
\hline BSI - social insecurity & $0.58 \pm 0.43$ & $0.94 \pm 0.87$ & $0.76 \pm 0.77$ & $0.58 \pm 0.42$ & $\mathrm{p}$ [stress $\mathrm{x}$ contraception $]=0.045$ \\
\hline BSI - aggressiveness & $0.66 \pm 0.66$ & $0.72 \pm 0.59$ & $0.55 \pm 0.55$ & $0.34 \pm 0.36$ & $\mathrm{p}$ [stress] $=0.036$ \\
\hline PSS & $15.04 \pm 5.70$ & $18.00 \pm 7.11$ & $15.74 \pm 7.57$ & $15.36 \pm 6.16$ & all p ns \\
\hline
\end{tabular}

NoOC = No Oral Contraception; OC = Oral Contraception; BMI = Body Mass Index; PMS = Premenstrual Symptoms; BSI = Brief Symptom Inventory; PSS $=$ Perceived Stress Scale. 
Monetary units earned from all decisions were disbursed after the experiment according to the following exchange ratio: $100 \mathrm{MU}=0.95 €$. The experiment was programmed and conducted with z-Tree software (Fischbacher, 2007).

\subsection{Procedure}

Participants were randomly assigned to the stress or control condition and were invited to the lab in groups of 6 people to the TSST-G (von Dawans et al., 2011). One week before the experiment, participants answered an online questionnaire on trait measures of trait anxiety and psychiatric symptoms. One day before the experiment, participants were reminded via email to not take any medication and to abstain from alcohol, caffeine, sports, and smoking $24 \mathrm{~h}$ prior to the experiment. Moreover, they were instructed to eat their usual breakfast and lunch on the day of the experiment, and to stop eating by $4 \mathrm{pm}$. The 2.5-hour sessions took place between 5.15 p.m. and 7.45 p.m. in order to control for diurnal variations in cortisol secretion. Upon arrival at the laboratory, participants were seated individually in the computer laboratory at their individual cubicle and were not allowed to communicate with each other. After reading and signing informed consent, participants were introduced to the saliva sampling method and were provided individually with a heart rate device (Polar ${ }^{\circledast}$ ). Subsequently, baseline measures of saliva cortisol and psychometric variables were taken. After that, written instructions regarding the decision paradigms were handed out. Participants had to read them carefully and answer control tasks. Those results were checked immediately by the experimenter. Other than the two participants we had excluded from the analyses (insufficient comprehension of the procedure), all participants answered the tasks correctly, indicating full understanding of the interaction procedure. Participants were then provided with the TSST-G stress or control instructions, and prepared for the task within five minutes. Subsequently, they were guided to the test room, where they received a summary of the procedure. On their way to the test room, they passed by the group of the interaction partners sitting in the waiting area. This guaranteed the credibility of the existence of the human interaction partners and the interactions themselves (in contrast to a fake scenario). While the target participants went to the test room, the group of interaction partners was guided to the computer laboratory. For the target participants, the sequence in the test room was: 12 min public-speaking task (stress) or simultaneous reading in a low voice (control), followed by the first set of 12 decisions in a paperpencil version (five min), then eight minutes mental arithmetic task (stress) or easy counting (control), followed by the second set of 12 decisions (five min). The two sets of the decision paradigms were given in randomized order. While participants provided another saliva sample and answered the repeated state questionnaire, their previously made decisions were matched with the second group's decisions in the computer laboratory where their interaction partners (second group) had in the meantime been instructed on the paradigm. After having finished providing the saliva sample and completing the state questionnaire in the test room, target participants entered the computer laboratory and were again seated at their respective individual cubicles. All participants had to remain in the lab until the last saliva measure was taken ( +80 min after the start of TSST-G procedure), then they were debriefed. For the final payoff, participants were given individual feedback screens for each of their 24 decisions so that they could understand the composition of their individual profit. They were then disbursed individually (sum of all 24 periods plus a flat fee). As described above, it was guaranteed in the instructions on the decision paradigms that all interactions would involve real human interaction partners. We strengthened our credibility by the fact that the target participants passed by the group of female interaction partners while entering the test room.

\subsection{Psychological stress response}

We used visual analog scales (VAS) to capture the psychological stress response (von Dawans et al., 2012). Participants had to rate their acute stress level (VAS Stress) as well as the wish to have a close person to be with them right now (VAS Closeness). The VAS scales were assessed together with every saliva sample at the following eight time points: at baseline $(-30 \mathrm{~min}$ relative to the start of the TSST-G), after the intro (Start of TSST-G), after the first part of the TSST-G $(+12 \mathrm{~min})$, after the second part of the TSST-G $(+25 \mathrm{~min})$, and four times during the recovery phase $(+35 \mathrm{~min},+45 \mathrm{~min},+60 \mathrm{~min},+$ $80 \mathrm{~min})$.

\subsection{Endocrine and autonomic stress response}

We measured the cortisol stress response using a commercially available sampling device (salivette; Sarstedt ${ }^{\circledast}$, NümbrechtRommelsdorf, Germany) eight times during the experiment together with the VAS. After each experimental session, samples were stored at $-20{ }^{\circ} \mathrm{C}$. For biochemical analyses of free cortisol concentration, saliva samples were thawed and spun at $3000 \mathrm{rpm}$ for $10 \mathrm{~min}$ to obtain $0.5-1.0 \mathrm{ml}$ clear saliva with low viscosity. Salivary cortisol concentrations were determined by a commercially available chemiluminescence immunoassay (CLIA; IBL Hamburg, Germany). Inter-and intraassay coefficients of variation were below $8 \%$. Three participants presented baseline levels above $30 \mathrm{nmol} / \mathrm{l}$ and were excluded from the cortisol analyses. For cortisol levels, the areas under the individual response curves with respect to ground (AUCG) and increase (AUCI) were calculated with the trapezoid formula, enabling an aggregated sensitive measure of physiological changes in cortisol over time (Pruessner, Kirschbaum, Meinlschmidt, \& Hellhammer, 2003).

Heart rate was measured as a marker of the sympathetic stress system using a wireless chest heart rate transmitter and a wrist monitor recorder (Polar RS800 TM, Polar Electro, Finland). We recorded beatto-beat heart rate data and calculated one minute mean values: five for resting baseline, five before the start of TSST-G, 30 for the duration of TSST-G (20 min) including the decision paradigm (10 min) and five after the end of the procedure. Due to technical problems, heart rate data were obtained from 83 participants in the final sample.

\subsection{Psychometric measures}

To characterize the four groups with regards to relevant psychometric measures, we applied the Brief Symptom Inventory (BSI) (Derogatis and Melisaratos, 1983; Franke, 2000) using the scales Somatization, Obsessive-Compulsiveness, Social Insecurity, Depressiveness, Anxiety, Aggressiveness, Phobia, Paranoid Thinking, and Psychoticism. To compare the level of chronic stress, we assessed the Perceived Stress Scale (PSS) (Cohen et al., 1983). Since we conducted the experiment during the luteal phase of the menstrual cycle, it was important to note whether the OC and no OC groups differed in their level of premenstrual symptoms. We therefore included the PMS Questionnaire (Ditzen et al., 2011). We used the German version of the State Trait Anxiety Inventory to measure general levels of anxiety (Spielberger et al., 1970).

\subsection{Statistical analyses}

For descriptive statistics and randomization checks (including baseline comparisons of the psychophysiological parameters), we conducted ANOVAS with the factors STRESS (stress and control) and CONTRACEPTION (contraception and no contraception: OC and NoC). To calculate the effects of stress and contraception over the curse of the experiment regarding the subjective parameters as well as cortisol and heart rate, we calculated repeated measurement ANOVAS with the within subject factor time (eight time points) and the between subjects- 
factors STRESS (stress and control) and CONTRACEPTION (contraception and no contraception: $\mathrm{OC}$ and $\mathrm{NoC}$ ). For the analyses of each behavioral paradigm we calculated ANOVAs with the between subjectfactors STRESS (stress and control) and CONTRACEPTION (contraception and no contraception: OC and NoC). In cases of significant differences between groups in BSI Social insecurity and BSI Aggressiveness we computed additional ANCOVAs with the between subjects-factors STRESS and CONTRACEPTION $(O C)$ and the covariates BSI Social insecurity and BSI Aggressiveness in order to statistically control for these differences. In cases of heterogeneity of covariance (Mauchly test of sphericity), we determined the significance of the results of the repeated measures ANOVAs via Greenhouse Geisser corrections. Effect sizes are reported as $\eta_{\mathrm{p}}{ }^{2}$ for ANOVAs and ANCOVAs. For the behavioral variables we calculated Cohen's $d$ to be able to relate the effect sizes to those in other studies. Data were analyzed using SPSS Version 24. All tests were two-sided, with the level of significance set at $\mathrm{p} \leq .05$.

\section{Results}

\subsection{Descriptive statistics and randomization checks}

Our groups did not differ in age, BMI, or their level of chronic stress measured via the PSS. There were no significant differences in PMS symptoms reported between groups, and no differences in trait anxiety. There was no difference in the total symptom severity regarding psychiatric symptoms, but we observed a significant stress $\mathrm{x}$ contraception interaction concerning BSI Social Insecurity $(\mathrm{F}[1,90]=4.146$, $\left.p=0.045, \eta_{p}{ }^{2}=0.044\right)$ and a main effect of stress for BSI Aggressiveness $\quad\left(F[1,90]=4.525, \quad p=0.036, \quad \eta_{p}^{2}=0.048\right) \quad($ see Table 1). To control for these differences and possible effects on behavior, the two scales were used as covariates when analyzing the behavioral variables in secondary analyses.

\subsection{Psychological stress responses}

We observed no baseline differences in VAS Stress or VAS Closeness (see Table 2). For VAS Stress the repeated measurement ANOVA revealed the expected effect of time $(F[4.711,424]=28.981, \mathrm{p} \leq 0.001$, $\left.\eta_{\mathrm{p}}{ }^{2}=0.244\right)$ as well as a significant time $\mathrm{x}$ stress interaction ( $\mathrm{F}[4.711$, $\left.424]=10.470, p \leq 0.001, \eta_{p}{ }^{2}=0.104\right)$. There also was a main effect of stress $\left(F[1,90]=9.757, p=0.002, \eta_{p}{ }^{2}=0.098\right)$. We detected the same pattern for the VAS Closeness: time $(F[3.489,314.025]=5.579$, $\left.\mathrm{p} \leq 0.001, \eta_{\mathrm{p}}{ }^{2}=0.058\right)$, time $\mathrm{x}$ stress interaction ( $\mathrm{F}[3.489$, $\left.314.025]=4.360, \mathrm{p}=0.003, \eta_{\mathrm{p}}{ }^{2}=0.046\right)$, main effect of stress ( $\mathrm{F}[1$, $90]=6.851, \mathrm{p}=0.010, \eta_{\mathrm{p}}{ }^{2}=0.071$ ). The main interaction of stress $\mathrm{x}$ contraception missed the 0.05 level of significance $(F[1,90]=2.753$, $\mathrm{p}=0.102, \eta_{\mathrm{p}}^{2}=0.029$ ). The stressNoOC group revealed the highest VAS Closeness levels over the course of the experiment on the descriptive level. Fig. 1 shows the "VAS closeness" and "VAS stress" responses to stress and control condition over the course of the experiment.

Table 2

Baseline characteristics with mean values \pm SD in each group.

\begin{tabular}{|c|c|c|c|c|c|}
\hline & Control_NoOC & Control_OC & Stress_NoOC & Stress_OC & $\mathrm{p}$ - value \\
\hline Cortisol & $\begin{array}{l}9.13 \pm 6.11 \\
n=25\end{array}$ & $\begin{array}{l}6.82 \pm 3.20 \\
n=24\end{array}$ & $\begin{array}{l}7.26 \pm 4.03 \\
\mathrm{n}=18\end{array}$ & $\begin{array}{l}8.66 \pm 4.40 \\
n=24\end{array}$ & $\mathrm{p}$ [stress $\mathrm{x}$ contraception] $=0.061$ \\
\hline Heart Rate & $\begin{array}{l}81.11 \pm 10.20 \\
\mathrm{n}=22\end{array}$ & $\begin{array}{l}82.44 \pm 9.70 \\
n=21\end{array}$ & $\begin{array}{l}80.09 \pm 11.32 \\
n=17\end{array}$ & $\begin{array}{l}87.03 \pm 11.40 \\
\mathrm{n}=23\end{array}$ & $\mathrm{p}[$ contraception $]=0.083$ \\
\hline VAS Stress & $\begin{array}{l}2.65 \pm 2.45 \\
n=26\end{array}$ & $\begin{array}{l}2.09 \pm 2.30 \\
\mathrm{n}=24\end{array}$ & $\begin{array}{l}2.11 \pm 2.16 \\
\mathrm{n}=19\end{array}$ & $\begin{array}{l}2.38 \pm 2.12 \\
\mathrm{n}=25\end{array}$ & all $\mathrm{p}$ ns \\
\hline VAS Closeness & $\begin{array}{l}1.44 \pm 1.94 \\
\mathrm{n}=26\end{array}$ & $\begin{array}{l}2.23 \pm 2.74 \\
\mathrm{n}=24\end{array}$ & $\begin{array}{l}2.34 \pm 2.65 \\
\mathrm{n}=19\end{array}$ & $\begin{array}{l}2.13 \pm 2.50 \\
\mathrm{n}=25\end{array}$ & all $\mathrm{p}$ ns \\
\hline
\end{tabular}

NoOC $=$ No Oral Contraception; OC $=$ Oral Contraception; VAS $=$ Visual Analog Scale.

\subsection{Physiological stress responses}

We found differences in cortisol at baseline for the interaction stress $\mathrm{p}=0.061, \eta_{\mathrm{p}}^{2}=0.040$ ). Nevertheless, we noted significant increases in cortisol over time $(\mathrm{F}[1.715,149.207]=16.160, \quad \mathrm{p} \leq 0.001$, $\eta_{\mathrm{p}}{ }^{2}=0.157$ ), and the expected time $\mathrm{x}$ stress interaction ( $\mathrm{F}[1.715$ $149.207]=28.807, \mathrm{p} \leq 0.001, \eta_{\mathrm{p}}^{2}=0.249$ ) with the expected increases over time for the stress condition compared to decreases in the control condition. Moreover, we observed a main effect for stress ( $\mathrm{F}[1$, $\left.87]=25.126, p \leq 0.001, \eta_{p}{ }^{2}=0.224\right)$ with higher cortisol levels in the stress condition over the course of the experiment. There were significantly higher total cortisol (AUCG) as well as increases in cortisol (AUCI) in the stress compared to control condition (AUCG: $F[1$, $87]=26.261, \quad \mathrm{p} \leq 0.001, \eta_{\mathrm{p}}^{2}=0.232 ; \quad$ AUCI: $F[1,87]=32.055$, $\mathrm{p} \leq 0.001, \eta_{\mathrm{p}}^{2}=0.269$ ).

The contraception group exhibited higher baseline heart rate levels (significant on a trend level, $F[1,79]=3.084, \mathrm{p}=0.083, \eta_{\mathrm{p}}{ }^{2}=0.038$ ). Moreover, time demonstrated a significant effect ( $F[9.048$, $\left.714.771]=35.140, \mathrm{p} \leq 0.001, \eta_{\mathrm{p}}^{2}=0.308\right)$, as did the expected time $\mathrm{x}$ stress interaction $(\mathrm{F}[9.048,714.771]=2.343, \quad \mathrm{p}=0.013$, $\left.\eta_{\mathrm{p}}^{2}=0.029\right)$. Again, stress revealed a main effect $(F[1,79]=5.177$, $\mathrm{p}=0.026, \eta_{\mathrm{p}}{ }^{2}=0.062$ ), as did contraception (significant on a trend level, $\mathrm{F}[1,79]=3.041, \mathrm{p}=0.085, \eta_{\mathrm{p}}{ }^{2}=0.037$ ). All psychological and physiological baseline levels are listed in Table 2. Fig. 1 shows the cortisol and heart rate responses to stress and control condition over the course of the experiment.

\subsection{Effects of stress and contraception on prosocial behavior, punishment} and risk

Stress increased trustworthiness $(\mathrm{F}[1,90]=4.291, \mathrm{p}=0.041$ $\left.\eta_{\mathrm{p}}^{2}=0.046\right)$ and sharing $\left(\mathrm{F}[1,90]=6.930, \mathrm{p}=0.010, \eta_{\mathrm{p}}{ }^{2}=0.071\right)$. There was no effect of OC and no significant interaction effect. Trust was not influenced significantly by either stress or OC. On a trend level $\left(\mathrm{F}[1,90]=3.097, \mathrm{p}=0.082, \eta_{\mathrm{p}}{ }^{2}=0.033\right)$ we observed a stress by OC interaction with lower levels of punishment in the stress condition in women without contraception and higher levels of punishment in the stress condition for women with OC (compared to control condition). Neither stress nor OC or the interaction had an impact on nonsocial risk behavior. Since we found significant differences between the groups in BSI Insecurity and BSI Aggressiveness we additionally conducted ANCOVAs to control for possible confounding influences on our behavioral variables. These analyses confirmed our previously reported results and again revealed significantly higher rates of trustworthiness (F $\left.[1,88]=4.299, \mathrm{p}=0.041, \eta_{\mathrm{p}}^{2}=0.047\right)$ and sharing $(\mathrm{F}[1,88]=7.643$, $\mathrm{p}=0.007, \eta_{\mathrm{p}}{ }^{2}=0.080$ ) in the stress- versus the control condition. Moreover, women without OC demonstrated higher rates of sharing (significant on a trend level, $F[1,88]=3.282, \mathrm{p}=0.073, \eta_{\mathrm{p}}{ }^{2}=0.036$ ) regardless of the condition. There were no differences between groups in trust (all $p>0.191$ ). We observed a trend towards stress $x$ contraception interaction in conjunction with punishment $(\mathrm{F}[1,88]=3.025$, $\mathrm{x}$ contraception (significant on a trend level, $\mathrm{F}[1,87]=3.604$,

140 

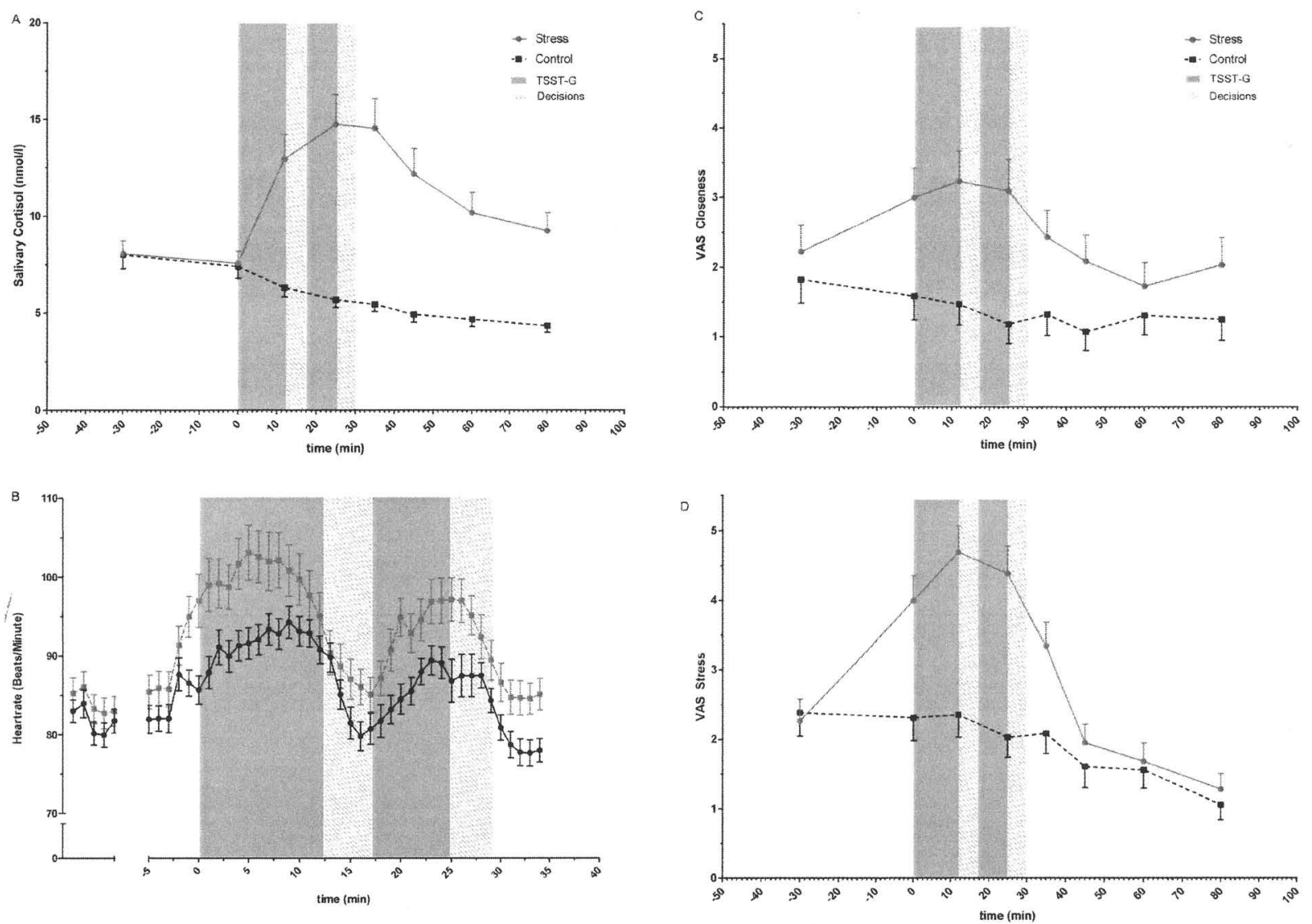

Fig. 1. Participants' (A) mean level of free salivary cortisol, (B) heart rate, (C) mean level of wish for closeness, and (D) mean level of subjective stress during the experimental session. Results are shown separately for the stress and control conditions. Time 0 was the start of the Trier Social Stress Test for Groups (TSST-G; von Dawans et al., 2011). Error bars indicate standard errors of the mean.

$\mathrm{p}=0.086, \eta_{\mathrm{p}}^{2}=0.033$ ) with lower levels of punishment in the stress condition in women without contraception and higher levels of punishment in the stress condition for women with OC (compared to control condition). Nonsocial risk behavior revealed neither effects of stress nor OC. There were no significant effects of the covariates in any of the models. BSI Aggressiveness exhibited an influence only on punishment on the trend level $\left(F[1,88]=2.846, p=0.095, \eta_{p}{ }^{2}=0.031\right)$ where higher levels of BSI Aggressiveness were associated with higher levels of punishment. To enable comparisons with the results of previous (e.g. von Dawans et al., 2012) and future studies on the effects of stress on behavior in male and female participants, we calculated Cohen's $\mathrm{d}$ for all behavioral variables for the factor stress vs. no-stress. We observed low to medium effects for trust $(d=0.20)$, trustworthiness $(d=0.41)$, sharing $(d=0.51)$, punishment $(d=-0.05)$, and risk $(d=-0.03)$. Figures of all behavioral results are presented in Fig. 2.

\section{Discussion}

Our study investigated the effects of acute psychosocial stress on social behavior in women with and without OC. The manipulation check showed significant increases in subjective and biological stress parameters in the stress condition compared to controls. On the behavioral level, stress increased trustworthiness and sharing. There were no significant influences of stress or OC on trust or non-social risk behavior. We did note an interaction between stress and $\mathrm{OC}$ on the trend level for punishment, which revealed lower levels in the stress condition compared to control condition in the no-OC women. The women with OC delivered higher levels of punishment in the stress group compared to the control group. Sharing revealed a trend towards overall higher rates in the women without OC.

Our results fall in line with findings in men demonstrating higher levels of prosocial behavior after stress (Berger et al., 2016; Buchanan and Preston, 2014; Margittai et al., 2015; von Dawans et al., 2012), and contribute important empirical evidence on the validity of the tendand-befriend concept of stress in women. We also detected a significant increase in the wish for closeness in the stress condition that accompanies the behavioral results and documents subjective-approach tendencies triggered by psychosocial stress. But what are the relevant mechanisms behind our results? Stress is known to prompt habitual behaviors and increase intuitive thinking while reducing deliberation (Margittai et al., 2016; Schwabe and Wolf, 2009; Yu, 2016). Interpreting our results, this may give the impression that the default mode of human behavior is prosocial. This is a pleasant thought but definitely too narrowly considered. Our paradigm may provide for a situation enabling participants to choose the prosocial way. Buchanan and Preston (Buchanan and Preston, 2014) reported that stress leads to prosocial behavior in immediate-need situations where the prosocial option is bearable and obviously needed by the interaction partner. Interestingly, we did not detect higher rates of trust in our stressed women. This might be because trust entails much higher social and financial risks than trustworthiness or sharing. In the two latter decisions, the payoff structure and final consequence is set and clear: the participant knows what she will get and actively decides on a share. With trust, she would need to risk that her interaction partner might not be trustworthy - resembling a risky situation characterized by uncertainty. The fact that in our previous study (von Dawans et al., 2012) 

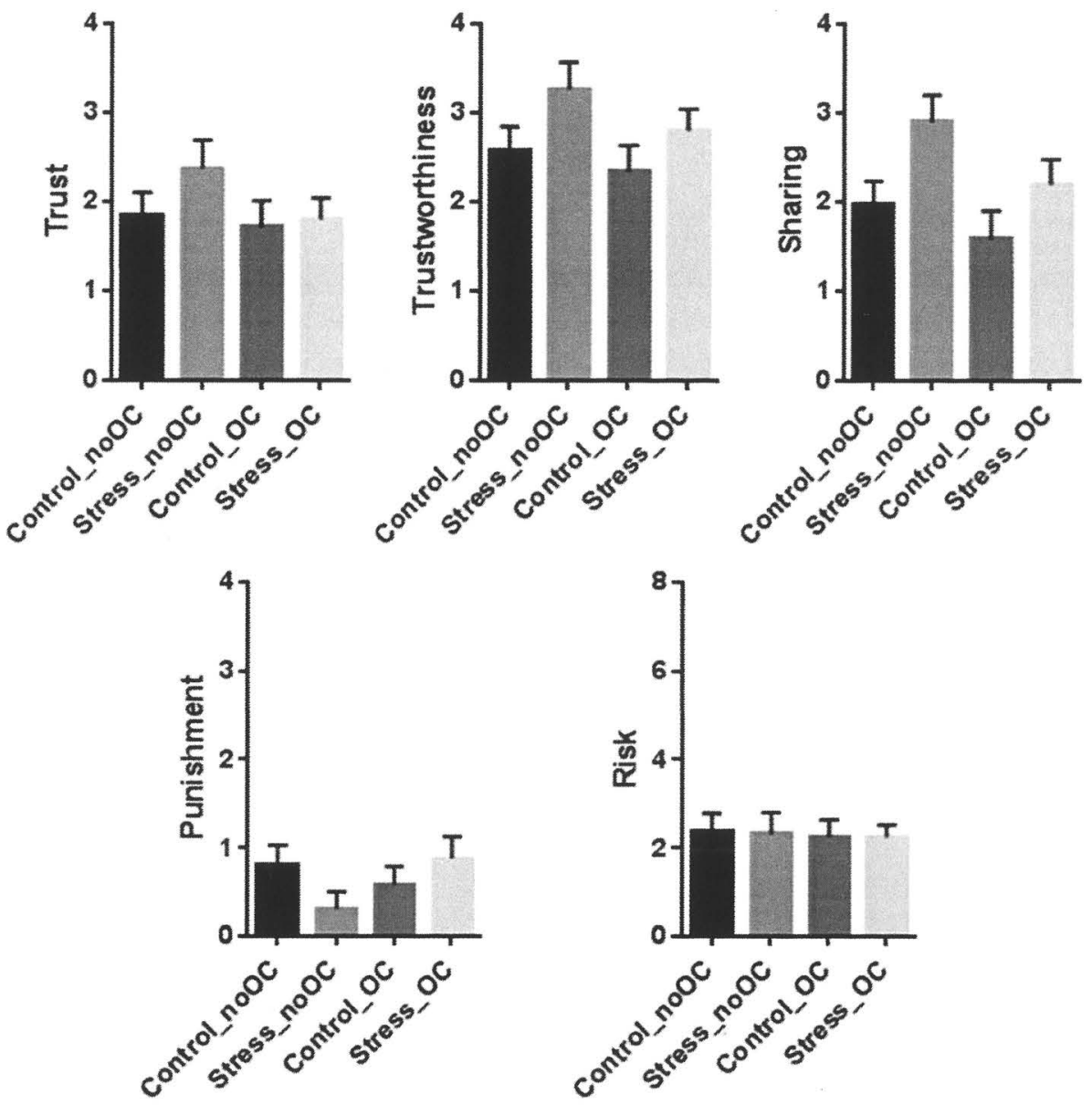

Fig. 2. Mean score in each game as a function of condition. Error bars indicate standard errors of the mean. TSST-G = Trier Social Stress Test for Groups (von Dawans et al., 2011).

we identified higher rates of trust during stress in men - which we now failed to observe in women - might be due to general sex differences in financial risk taking already documented (Charness and Gneezy, 2012). Moreover, our paradigm employed slightly different parameters than those we used in the 2012 study: that study was conducted in another lab and another country (Switzerland versus Germany). For direct comparison of the effects (and effect sizes) of stress on social behavior in men compared to women, future investigations need to include both sexes in one study under identical experimental conditions. Future meta-analyses of studies on the effects of stress on social behavior may use our data for evaluation. In the meantime, a comparison of the present study's effect sizes and of those detected in male participants (von Dawans et al, 2012) should be interpreted cautiously.

Acute psychosocial stress is known to increase social cognition (Smeets et al., 2009; Wolf et al., 2015) and the self-other distinction (Tomova et al., 2014). Perhaps increased perspective-taking or higher levels of empathy during acute stress foster prosocial behavior. Taylor (Taylor, 2006; Taylor et al., 2000) claimed the neuropeptide oxytocin as an important modulator of the tend-and-befriend strategy. The neuropeptide oxytocin is released during acute stress in animals and humans (Engert et al., 2016; Jong et al., 2015; Landgraf and Neumann, 2004) and is associated with social behavior in both animals (Neumann, 2008) and humans (Heinrichs et al., 2009; Meyer-Lindenberg et al., 2011). Studies using intranasal oxytocin in humans found higher levels of prosocial behavior in men (Kosfeld et al., 2005) and couples (Ditzen et al., 2009) as well as increases in social cognition, empathy, and mind-reading (Domes et al., 2007) by oxytocin. A study on empathy for pain revealed higher other-perspective empathy for pain than selfperspective empathy for pain after oxytocin administration (Abu-Akel et al., 2015). In addition, oxytocin was found to reduce stress responses in humans (Heinrichs et al., 2003). Since oxytocin is released during stress and seems to boost recovery from stress (Engert et al., 2016), the increase in prosocial behaviors via endogenous oxytocin release during stress may be part of an inherent psychobiological coping framework activated in healthy men (von Dawans et al., 2012) and - as our study shows - in women, too. Direct physiological effects of oxytocin in combination with increases in prosocial behavior during stress may enable future social interaction and support with all their beneficial effects (Ditzen and Heinrichs, 2014).

Our results failed to verify distinct significant differences in either the stress response or behavioral effects of stress between women with hormonal contraception and women in the luteal phase of the cycle. We noted only trend effects for overall higher levels of sharing behavior in women without contraception, irrespective of the stress condition. An interaction effect for punishment revealed higher levels of punishment under stress in women with OC and lower levels of punishment after stress in women without OC. Future studies will need to shed light on possible differences over the course of the menstrual cycle in comparison to OC, as sex hormones are known to modulate oxytocin's effects (Scheele et al., 2016). Therefore, future studies should include measures of progesterone and estradiol, as well as investigate different stress inducing methods like non-social stressors (Cold Pressor Test) and pharmacological stimulations of the HPA axis and the SAM system in order to reveal behaviorally relevant components of the stress induction 
and response. Furthermore, studies will need to investigate social interactive behavior in the direct human face-to-face mode that risks losing experimental control while gaining external validity so as to generalize the results to everyday human behavior. Another factor is that in our study, women always interacted with other women. As our previous results in women suggest stronger preferences for feminized male faces after stress as compared to a control condition (Ditzen et al., 2017), one could assume that stress in women affects interaction behavior with men and women in different ways.

In addition, we wish to point out that we did not administer OC in a randomized controlled setting but instead used naturally occurring groups that voluntarily did or did not use OC. This carries the risk that we may have overseen influences from factors other than the OC's. Future studies may either employ a random experimental administration of OC or measure progesterone and estradiol (as stated above). Moreover, studies systematically investigating potential differences in OC users vs. non - OC users with qualitative and quantitative methods may shed light upon this problem.

Since several personality variables may not just influence social behavior in general but possibly also moderate the stress response (Kudielka et al., 2009), as well as the effects of acute stress on behavior (Buchanan and Preston, 2014) we assessed influencing variables that need to be controlled. Although our groups differed significantly in their level of social insecurity and aggressivess, those variables did not confound the effects of stress on behavior. This of course does not disprove a possible underlying correlation between social insecurity or aggressiveness and the effects of stress on behavior in general, because we only included healthy women and the apparent differences despite randomization might have been too small to be relevant. To address those questions, future studies will need to include participants with a broader range of aggressiveness or social insecurity. Studies including patients with social anxiety disorder or borderline personality disorder, for example, might be highly relevant to detect potential behavioral differences and difficulties in coping with acute social stressors.

In summary: our data reveal higher levels of trustworthiness and sharing after stress in women. We thus provide the first clear evidence of tend-and-befriend behavior after acute stress in women - who were the actual target group of the tend-and-befriend theory (Taylor, 2006; Taylor et al., 2000). Our findings document approach tendencies in healthy women during acute stress which might foster future positive social exchange processes and the acceptance of social support - and may reflect an inherent stress coping mechanism.

\section{Funding}

Bernadette von Dawans and Markus Heinrichs gratefully acknowledge grant support from the Innovation Fund of the University of Freiburg.

\section{Declaration of conflicting interests}

The authors have declared that they have no conflicts of interest with respect to their authorship or the publication of this article.

\section{Acknowledgements}

We thank Julia Albicker, Diana Bickel, Hannah Brüderl, Esther Germain, Lily Kordes, Antonia Vehlen and Adrian Willimsky for their help with recruiting participants, data collection and management of the study.

\section{References}

Abu-Akel, A., Palgi, S., Klein, E., Decety, J., Shamay-Tsoory, S., 2015. Oxytocin increase empathy to pain when adopting the other- but not the self-perspective. Soc. Neurosci. 10, 7-15. hitps: doi.org/10.1080/17470919.2014.948637.

Aron, A., Melinat, E., Aron, E.N. Vallone, R.D. Bacor, R.J., 1997. The experimental generation of interpersonal closeness: a procedure and some preliminary findings Pers. Soc. Psychol. Bull. 23, 363-377.

Berger, J., Heinrichs, M., von Dawans, B., Way, B.M., Chen, F.S., 2016. Cortisol modulates men's affiliative responses to acute social stress. Psychoneuroendocrinology 63, 1-9. hutps://doi.org/10.1016/1.psyneuen.2015.09.004.

Buchanan, T.W., Preston, S.D., 2014. Stress leads to prosocial action in immediate need situations. Front. Behav. Neurosci. 8. https://doi.org/10.3389/fnbeh.2014.00005.

Cannon, W.B., 1939. The Wistom of the Body, 2nd ed. Nuiton \& Co., uxford, England.

Charness, G., Gneezy, U., 2012. Strong evidence for gender differences in risk taking J. Econ. Behav. Organ. 83, 50-58. https://dot.org/10.1016/j.jebo.2011.06.007. Gender Differences in Risk Aversion and Competition.

Chrousos, G.P., 2009. Stress and disorders of the stress system. Nat. Rev. Endocrinol. 5, 374-381. https://doi.org/10.1038/irendo. 2009.106

Cohen, S., Kamarck, T., Mermelstein, R., 1983. A global measure of perceived stress. I. Health Soc. Behav. 385-396.

Derogatis, L.R., Metisaratos, N., 1983. The brief svmptom inventory: an introductory report. Psychol. Med, 13, 595-605.

Ditzen, B., Heinrichs, M., 2014. Psychobiology of social support: the social dimension of stress buffering. Restor. Neurol. Neurosci. 32, 149-162. bttps://doi.org/10.3233, RNN-139008.

Ditzen, B., Schaer, M., Gabriel, B., Bodenmann, G., Ehlert, U., Iteinrichs, M., 2009. Intranasal axytocin increases positive communication and reduces cortisol levels during couple conflict. Biol. Psychiatry 65. 728-731.

Ditzen, B., Nussbeck, F., Drobnjak, S., Spörri, C., Wüest, D., Ehlert, U., 2011. Validierung eines deutschsprachigen DSM-IV-TR basierten Fragebogens zum prämenstruellen Syndrom. Z. Für Klin. Psychol. Psychother. 40, 149-159. hetps://doi.org/10.1026, 1616-3443/a000095.

Ditzen, B., Palm-Fischbacher, S., Gossweiler, L., Stucky, L., Ehlert, U., 2017. Effects of stress on women's preference for male facial masculinity and their endocrine correlates. Psychoneuroendocrinology 82, 67-74. https://dol.org/10.1016/j.psyneuen. 2017.05006.

Domes, G., Heinrichs, M., Michel, A., Berger, C., Herpertz, S.C., 2007. Oxytocin improves "mind-reading" in humans. Biol. Psychiatry 61.731-733.

Engert, V., Koester, A.M., Riepenhausen, A., Singer, T., 2016. Boosting recovery rather than buffering reactivity: higher stress-induced oxytocin secretion is associated with increased cortisol reactivity and faster vagal recovery after acute psychosocial stress. Psychoneuroendocrinology 74, 111-120. https://doi.org/10.1016/j.psyneuen.2016. $08,029$.

Fischbacher, U., 2007. z-Tree: Zurich toolbox for ready-made economic experiments. Exp. Econ. 10, 171-178. https://dol.org/10.1007/s10683-006-9159-4

Foley, P., Kirschbaum, C., 2010. Human hypothalamus-pituitary-adrenal axis responses to acute psychosocial stress in laboratory settings. Neurosci. Biobehav. Rev. 35, 91-96. https://doi.nrg/10.1016/j.neubiorev.2010.01.010.

Franke G.H. 2000 . Brief Symptom Inventory. Beltz, Göttingen.

Heinrichs, M., Baumgarmer, T. Kirschbaum, C, Ehlert, U, 2003. Social support and oxytocin interact to suppress cortisol and subjective responses to psychosocial stress. Biol. Psychiatry 54, 1389-1398.

Heinrichs, M., von Dawans, B., Domes, G., 2009. Oxytocin, vasopressin, and human socia behavior. Front. Neuroendocrinol. 30, 548-557.

Jong, T.R., de, Menon, R., Bludau, A., Grund, T., Biermeier, V., Klampfl, S.M., Jurek, B., Bosch, O.J., Hellhammer, J., Neumann, I.D., 2015. Salivary oxytocin concentrations in response to running, sexual self-stimulation, breastfeeding and the TSST: the Regensburg Oxytocin Challenge (ROC) study. Psychoneuroendocrinology 62, 381-388. hrtps://doi.org/10.1016/j.psyneuen.2015.08.027.

Karatsoreos, I.N., McEwen, B.S., 2011. Psychobiological allostasis: resistance, resilience and vulnerability. Trends Cogn. Sci. 15, 576-584. https://doi org/10.1016/j.tics. 2011.10 .005$.

Kemeny, M.E., Schedlowski, M., 2007. Understanding the interaction between psychosocial stress and immune-related diseases: a stepwise progression. Brain Behav. Immun. 21, 1009-1018. https://doi.org/10.1016/j,bbi.2007.07.010.

Kirschbaum, C., Pirke, K.-M., Hellhammer, D.H., 1993. The 'Trier Social Stress Test'-a tool for investigating psychobiological stress responses in a laboratory setting. Neuropsychobiology 28, 76-81.

Kirschbaum, C. Kudielka, B.M., Gaab, J., Schommer, N.C., Hellhammer, D.H., 1998 Impact of gender, menstrual cycle phase, and onal contraceptives on the activity of the hypothalamus-pituitary-adrenal axis. Psychosom. Med. 61, 154-162.

Kosfeld, M., Heinrichs, M., Zak, P.J., Fischbacher, U., Fehr, E., 2005. Oxytocin increases trust in humans. Nature 435, 673-676

Kudielka, B.M., Hellhammer, D.H., Wüst, S., 2009. Why do we respond so differently? Reviewing determinants of human salivary cortisol responses to challenge. Psychoneuroendocrinology 34, 2-18. hitps://toi.org/10.101b/i.psyneuen.2008.10. 004

Landgraf, R., Neumann, I.D., 2004. Vasopressin and oxytocin release within the brain: a dynamic concept of multiple and variable modes of neuropeptide communication. Front. Neuroendocrinol. 25, 150-176. https://doi.org/10.1016/.yfrne.2004.05.001.

Margittai, Z., Strombach, T., van Wingerden, M., Joëls, M., Schwabe, L., Kalenscher, T., 2015. A friend in need: time-dependent effects of stress on social discounting in men Horm. Behav. 73, 75-82. https://dolorg/10.1016/j, wheh 2015.05.019.

Margittai, Z., Nave, G., Strombach, T., van Wingerden, M., Schwabe, L., Kalenscher, T., 
2016. Exogenous cortisol causes a shift from deliberative to intuitive thinking. Psychoneuroendocrinology 64, 131-135. hrrps:// dol.org/10.1016/j.psyneuen.2015. 11.018

McEwen, B.S., Gray, J.D., Nasca, C., 2015. 60 YEARS OF NEUROENDOCRINOLOGY: redefining neuroendocrinology: stress, sex and cognitive and emotional regulation. J. Endocrinol. 226, T67-T83. https:'/doi.org /10.1530/JOE-15-0121.

Ménard, C., Pfau, M.L., Hodes, G.E., Russo, S.J., 2017. Immune and neuroendocrine mechanisms of stress vulnerability and resilience. Neuropsychopharmacol. Off. Publ. Am. Coll. Neuropsychopharmacol. hitps://doi.org/10.1038/npp.2016.90.

Meyer-Lindenberg, A., Domes, G., Kirsch, P., Heinrichs, M., 2011. Oxytocin and vasopressin in the human brain: social neuropeptides for translational medicine. Nat. Rev Neurosci. 12, 524-538. https://dol.otg/10.1038/nm3044.

Neumann, I.D., 2008. Brain oxytocin: a key regulator of emotional and social behaviours in both females and males. J. Neuroendocrinol. 20, 858-865. https: /doi.ora/10 in both females and males. J. Neur.

Pruessner, J.C., Kirschbaum, C., Meinlschmid, G., Hellhammer, D.H., 2003. Two formulas for computation of the area under the curve represent measures of total hormone concentration versus time-dependent change. Psychoneuroendocrinology 28 , 916-931. https://dol.org/10.1016/\$0306-4530(02)00108-7.

Roelofs, K., 2017. Freeze for action: neurobiological mechanisms in animal and human freezing. Philos. Trans. Biol. Sci. 372https://doi.org/10.1098/rstb.2016.0206. 20160206.

Scheele, D., Plota, J., Stoffel-Wagner, B., Maier, W., Hurlemann, R., 2016. Hormona contraceptives suppress oxytocin-induced brain reward responses to the partner's face. Soc. Cogn. Affect. Neurosci. 11, 767-774. https://doi.org/10.1093/sean/ nSV 157.

Schwabe, L., Wolf, O.T., 2009. Stress prompts habit behavior in humans. J. Neurosci. 29, 7191-7198. https//dolorg/10.1523/JNEUROSC1.0979-09.2009.

Schwabe, L., Wolf, O.T., 2010. Learning under stress impairs memory formation. Neurobiol. Learn. Mem. 93, 183-188. https://dol.org/10.1016/f.nlm.2009.09.009. Smeets, T., Dziobek, I., Wolf, O.T., 2009. Social cognition under stress: differential effects of stress-induced cortisol elevations in healthy young men and women. Horm. Behav. 55, 507-513. https://doi.org/10.1016/j. yhbeh.2009.01.011.

Spielberger, C., Gorsuch, R., Lushene. R., 1970. Manual for the Statetrait Anxiet Inventory, Consulting Psychologists Press, Palo Alto. CA.

Taylor, S.E, 2006. Tend and befriend biobehavioral bases of affiliation under stress. Curt. Dir. Psychol Sci, 15, 273-277.

Tavlor, S.E., Klein, L.C. Lewis, B.P., Gruenewald, T.L., Gurung, R.A., Updegraff, J.A. 2000. Biobehavioral responses to stress in females: tend-and-befriend, not fight-orAight. Psychol. Rer. 107, 411-429.

Tomova, L., von Dawans, B., Heinrichs, M., Silani, G., Lamm, C., 2014. Is stress affecting our ability to tune into others? Evidence for gender differences in the effects of stres. on self-other distinction. Psychoneuroendocrinology 43, 95-104. https:/'dol.org/10. 1016/j.psyneuen.2014.02.006.

Tomova, L., Majdandžić, J., Hummer, A., Windischberger, C., Heinrichs, M., Lamm, C., 2017. Increased neural responses to empathy for pain might explain how acute stress increases prosociality. Soc. Cogn. Affect. Neurosci. 12, 401-408. https://doi.org/10. 1093/scan/nsw146. nsw146.

von Dawans. B., Kirsehbaum. C., Heinrichs, M., 2011. The Trier Social Stress Test for Groups (TSST-G): a new research tool for controlled simultaneous social stress exposure in a group format. Psychoneuroendoctinology 36, 514-522.

von Dawans, B., Fischbacher, U., Kirschbaum, C., Fehr, E., Heinrichs, M., 2012. The social dimension of stress reactivity: acute stress increases prosocial behavior in humans. Psychol. Sci. 23, 651-660. https://doi.org/10.1177/0956797611431576.

Wolf, O.T., Schulte, J.M., Drimalla, H., Hamacher-Dang, T.C., Knoch, D., Dziobek, I., 2015. Enhanced emotional empathy after psychosocial stress in young healthy men. Stress Int. J. Biol. Stress 18, 631-637. https:/doi.org/10.3109/10253890.2015. 1078787.

Yu, R., 2016. Stress potentiates decision biases: a stress induced deliberation-to-intuition (SIDI) model. Neurobiol. Stress 3, 83-95. https://doi.org/10.1016/j,yastr.2015.12. 006. 